East African Journal of Science, Technology and Innovation, Vol. 2 (3): June 2021

This article is licensed under a Creative Commons license, Attribution 4.0 International (CC BY 4.0)

\title{
Effects of poultry litter and inorganic fertilizer on growth and productivity of Rhizobia inoculated and non-inoculated beans
}

\author{
${ }^{1}$ MUBIRU D., ${ }^{1 *}$ OLET E. A. \\ ${ }^{1}$ Department of Biology, Mbarara University of Science and Technology, P. O. Box 1410, Mbarara, Uganda \\ *Corresponding author: eolet@must.ac.ug
}

\begin{abstract}
Agriculture has been the most contributing sector towards Uganda's economy. However, its output has always been hampered by declining soil fertility leading to reduced yields, increased agricultural losses and malnourishment among low income earners. In Uganda, there is scanty research about the effectiveness of either organic or inorganic fertilizers in crop production. Therefore, there was need to establish the effectiveness of inorganic fertilizer (N: P: K; 17:17:17) and organic fertilizer (poultry manure/litter) on the growth, and productivity of rhizobia inoculated and non-inoculated bio-fortified NAROBEAN 2 variety, which is rich in iron and zinc, highly yielding and drought resistant. A randomized complete block design experiment was conducted at Mbarara Zonal Agricultural Research and Development Institute (MBAZARDI). Poultry litter was applied at the rate of (10t/ha), N: P: K 17:17:17 at $20.3 \mathrm{~kg} \mathrm{ha}^{-1}$ and Rhizobia at 250g per $15 \mathrm{~kg}$ of beans. Treatments were; Rhizobia + N: P: K 17:17:17 (M 1), Rhizobia + Poultry litter (M 2), Rhizobia only (M 3), Poultry litter only (M 4), N: P: K 17:17:17 only (M 5) and the control (M 6). Growth parameters included number of leaves, branches, and shoot height; and productivity parameters included number of pods produced per plant and economic yield. Statistical analyses were done at $5 \%$ level of significance. The growth parameters showed no significant difference $(P$ $>0.05)$ while the bean grain yield and productivity were significantly different $(p<0.05)$ under the various treatments. Rhizobia + Poultry litter and N: P: K 17:17:17 only, produced the highest effect on both growth and productivity as compared to other treatments. Application of rhizobia with poultry manure was the best soil treatment for increasing the growth and productivity of NAROBEAN 2. This will increase production, food security, abate malnutrition, and sustainably improve soil quality.
\end{abstract}

Keywords: Bio-fortified, growth, productivity, inoculated, non-inoculated, Rhizobia, NAROBEAN 2

Cite as: Mubiru and Olet, (2021). Effects of poultry litter and inorganic fertilizer on growth and productivity of Rhizobia inoculated and non-inoculated beans. East African Journal of Science, Technology and Innovation 2(3).
Received: $\quad 21 / 09 / 20$

Accepted: $\quad 20 / 03 / 21$

Published: 25/06/21

\section{Introduction}

Phaseolus vulgaris L. is a group of common beans that belongs to the family Leguminosae (Fabaceae), the "Pea family". It is among the five cultivated species of genus Phaseolus and is third in importance after soya beans and peanuts (Broughton et al., 2003). Legumes are vital substitutes for meat due to their protein content of 20 to $30 \%$ (Al-abdalall, 2008). Beans are one of the globally vital legumes that have been used for several centuries due to their nutritional values (Energy per 100g: Carbohydrates; $127 \mathrm{kcal}$, Sugars; $0.32 \mathrm{~g}$, Dietary fiber; $7.4 \mathrm{~g}$, Minerals per 100g: Calcium; 28 mg, Iron; 2.94 mg, Magnesium; $45 \mathrm{mg}$, Zinc; $1.07 \mathrm{mg}$, Sodium; $2 \mathrm{mg}$, Potassium; $403 \mathrm{mg}$, Vitamins per 100g; Vitamin C; $1.2 \mathrm{mg}$, 
Vitamin $\mathrm{K} ; 8.4 \mu \mathrm{g}$, Vitamin E; $0.03 \mathrm{mg}$, Thiamine $\left(B_{1}\right) ; 0.16 \mathrm{mg}$, Riboflavin $\left(\mathrm{B}_{2}\right) ; 0.058 \mathrm{mg}$, Niacin $\left(\mathrm{B}_{3}\right) ; 0.578 \mathrm{mg}$, Pyridoxine $\left(\mathrm{B}_{6}\right) ; 0.12 \mathrm{mg}$ (USDA Nutrient Database, (http://ndb.nal.usda.gov/ndb/search/list.). According to Mauyo et al., (2007), beans are the most widely grown pulses second to maize and are a major food source of food security in East Africa. Also, they are the main grain legume crop in Eastern and Southern Africa (Katungi et al., 2009). Birachi, et al., (2011) reported production and marketing of common bean in Burundi as a potential pathway for improving rural livelihoods and showed common beans as being an important source of human dietary protein and calories. However, there has been slow increase in agricultural production in Africa due to the changing climate, low application of adaptive scientific and technological methods in production and the failure by most of the farmers to intensify agricultural production in the way that maintains and improves the declining soil fertility. The declining soil fertility with low adoption rates and use of productivity enhancing inputs were among the main challenges reportedly affecting the Uganda's agricultural sector (MAAIF, 2010). This, as a result, has reduced the nutritional composition of the crops grown on the nutrient-deprived soils in the various agroecological zones across Uganda. There have been many cases of malnutrition registered in the world and this has been attributed to the low nutritional food consumed by the population. According to (UNICEF-WHOThe World Bank, 2017), nearly half of the deaths of children under 5 years were widespread in Asia and Africa due to malnourishment. This was attributed to lack of important micronutrients, iron, zinc and vitamin $\mathrm{A}$ in the diet. Iron deficiency is one of the commonest micronutrient deficiencies in the world making Iron Deficiency Anaemia (IDA) a global health concern. 24.8\% (1.62 billion people) of the global population are affected by anaemia with the highest prevalence among the preschool age children (47.4\%). Africa reportedly had the highest (47.5-67.6\%) proportion of preschool age children, pregnant and non-pregnant women. Uganda was mapped among the countries with anaemia as a severe $(\geq$ $40.0 \%)$ public health problem among the preschool children and pregnant mothers (De Benoist \& Mclean, 2008). It is severely affecting a big proportion of children under 5 years and women of reproductive age (Nankinga \& Aguta, 2019). In 2006, $73 \%$ of children in Uganda were anaemic, 50\% in 2011 and 53\% in 2016. Anaemic prevalence among women varied from $49 \%$ in $2006,23 \%$ in 2011 and $32 \%$ in 2016, this was partly attributed to poor households (Nankinga \& Aguta, 2019). Zinc enables the body to utilize the carbohydrates, proteins and fats, strengthens the immune system and arguments wound healing. Malnourishment tends to intensify provided no remediation or intervention is done.

Beans are consumed by all the income classes and are one of the principal sources of food nutrients for people in the lower income bracket in Uganda. Therefore, one of the multi-sectorial strategies to cub malnutrition in the country was the release of five bio-fortified drought-tolerant bean varieties in 2016; three bush beans (NAROBEAN 1, 2, 3) and two climbing growth types (NAROBEAN 4C and $5 \mathrm{C}$ ). These were evaluated for their high yield potential, NAROBEAN 1, 2, 3 (1500-2000 kg per hectare) and NAROBEAN 4C, 5C (2500-3700 kg per hectare) (Booklets I Mpeke Town, n.d.); nutritional value (Guide 2 Uganda, 2016), accumulating iron (65.3-69 ppm) and zinc (32.1$34.7 \mathrm{ppm}$ ) micronutrients. In addition, they were found to be drought and disease tolerant (Georgina, 2016) and have less cooking time ( ICRISAT, 2017). Therefore, if production is boosted, the varieties can produce a cheap source of nutrients among the low-income earning communities and as well produce high yields, despite the prevalence of climate change as evident in the constant seasonal changes in Uganda.

The NAROBEAN 2 is one of the most supplied varieties by MBAZARDI to farmers and also is the most commonly grown variety by the farmers in south western low lands of Uganda (Mr. John Bosco Muhumuza, Pers Comm). MBAZARDI encourages farmers to treat the seeds with rhizobia inoculant, which is supplied by Biological Nitrogen Fixation Makerere University, prior to planting so as to maximise the yields. Biological Nitrogen Fixation Makerere University, apart from Madhavani Ltd, is the second plant producing inoculants in Uganda. This was established with the aid of the United 
States Agency for International Development (USAID) in 1990 (Bala et al., 2011). Since then, it has been producing rhizobia inoculants for agricultural input in Uganda. According to Ravikumar (2012), inoculation of Vigna mungo (Linn.) and $V$. radiata (L.) with carrier-based rhizobia produced pulses with greater; height, fresh weight, number of roots, nodules, number of leaves, shoots, pods, pod length, seed weight compared to the controls. However, the productivity of the variety is likely to be hindered by the constantly declining soil fertility on most farmlands as a result of persistent cultivation without fallowing periods and fertilizer application. Nekesa et al., (1999) showed that the low productivity of beans and maize cropping system in Uganda was due to many factors including the declining soil fertility. Akanbi et al., (2007) recommended fertilizer application for increasing crop yields. Presently, fertilizer application has become vital to increase productivity and feed the constantly increasing population.

Organic and inorganic fertilizers are both potential sources of mineral nutrient elements. There is still a growing dependence on use of inorganic fertilizers on both commercial and subsistence scales in crop production (Masarirambi et al., 2010). Roberts, (2009) reported the capacity of inorganic fertilizers to increase output in grain production from 40 to $60 \%$. Inorganic fertilizers have been used by farmers and serve a variety of advantages including being quickly absorbed and utilized by crops (Mofunanya et al., 2015). The increasingly rising demand for organically produced food renders a need for more exploration of the efficiency of organic fertilizers too. They improve nutrient bioavailability, soil structure, cation

\section{Materials and methods}

\section{Experimental design}

Pest free, equal sized, wholesome biofortified NAROBEAN 2 healthy seeds, were obtained from NARO MBAZARDI farm stores. An experimental site was established at MBAZARDI using a Randomized Complete Block Design (RCBD) with three replicates to control for local exchange capacity, soil $\mathrm{pH}$ microbial activity and water holding capacity of the soil (Muhammad \& Khattak, 2009). All these soil amendments using organic fertilizers have minimal negative ecological impacts on the environment. However, there are still gaps in knowledge about the yield response of rhizobia inoculated biofortified NAROBEAN 2 to both organic and inorganic fertilizers in Uganda. Poultry manure/litter, an organic fertilizer, is known to be nutrient rich and is readily available at low costs in rural communities (Ragagnin et al., 2013). It is composed of beddings like sawdust pine shavings and peanut hulls, mixed with chicken feaces and urine. It contains primary plant nutrients $\left[\left(\right.\right.$ nitrogen $(\mathrm{N})$, phosphorus $\left(\mathrm{P}_{2} \mathrm{O}_{5}\right)$ and potassium $\left(\mathrm{K}_{2} \mathrm{O}\right)$ ], secondary nutrients [(calcium (Ca), magnesium $(\mathrm{Mg}$ ) and sulphur (S)], micro nutrients [(copper, iron, manganese, zinc and boron)] (Alabama Cooperative Extension System (2019). Bolan et al., (2010) found each kilogram of dry weight of layer litter to contain $32.8 \mathrm{~g}$ of nitrogen, 10.8 g-phosphorus, 15.2 g-potassium, $18.5 \mathrm{~g}$-calcium, 6.2g- magnesium and $8.5 \mathrm{~g}$ sulphur. Also, poultry litter is mineralized faster compared to the other animal manures (Mbatha, 2008) and therefore is more superior to other animal manure. Compound N: P: K 17:17:17 is one of the most used inorganic fertilizers by farmers in Uganda, accounting for $60 \%$ of the total imported inorganic fertilizers, and contains $\mathrm{N}, \mathrm{P}$ and $\mathrm{K}$ as essential nutrient elements (Godfrey \& Dickens, 2015). This study therefore focused on comparing the effectiveness of selected organic fertilizer; Poultry litter and Inorganic fertilizer; N: P: K 17:17:17, on the growth, and productivity of inoculated and noninoculated NAROBEAN 2 variety to increase production, improve food security, alleviate malnutrition and reduce poverty levels among local communities in Uganda.

variability within the plot. Each block was then partitioned into six plots measuring $2 \mathrm{~m}$ by $2 \mathrm{~m}$ and separated by $1 \mathrm{~m}$ from the other. Simple random sampling was used during fertilizer application per plot in each block. Poultry litter was prepared by active pile compositing 
traditional method and applied 2 weeks before planting, and regularly turned until it completely decomposed as recommended by Ellis et al., (2013). N: P: K 17:17:17 was applied at a rate of $20.3 \mathrm{~kg} \mathrm{ha}^{-1}$ after one week of planting by side dressing method.

\section{Inoculation of the bean seeds with Rhizobia}

Three hundred (300) $\mathrm{ml}$ of clean warm water were transferred into a trough for easier mixing. Two table spoons of table sugar were added to water and mixed thoroughly to obtain a sticky solution. This was followed by addition of half a kilogram of seeds until they were evenly coated with the sticky solution. Rhizobia inoculant was then poured into the bean seeds, mixed slowly by shaking until all seeds were uniformly coated with the inoculant (Drew et al., 2012). The seeds were immediately planted in moist soil. There were six treatments in the experiment with three replications (Table 1).

Table 1. Treatment combinations and their respective codes used in the study

\begin{tabular}{ll}
\hline Treatment code & Treatment combination \\
\hline M 1 & Rhizobia $\left(250 \mathrm{~g} 15 \mathrm{~kg}^{-1}\right.$ of seeds $)+\mathrm{N}:$ P: K 17:17:17 (20.3 kg ha-1) \\
M 2 & Rhizobia (250 g $15 \mathrm{~kg}^{-1}$ of seeds) + Poultry litter $\left(10 \mathrm{t} \mathrm{ha}^{-1}\right)$ \\
M 3 & Rhizobia only $(250 \mathrm{~g}$ per $15 \mathrm{~kg}$ of seeds $)$ \\
M 4 & Poultry litter $\left(10 \mathrm{t}^{-1}\right)$ only \\
M 5 & N: P: K 17:17:17 $\left(20.3 \mathrm{~kg} \mathrm{ha}^{-1}\right)$ only \\
M 6 & Control (no application amendment) \\
\hline
\end{tabular}

\section{Planting and crop management practices}

The seeds were planted 1 to $1 \frac{1 / 2}{2}$ inches deep, spaced $50 \mathrm{~cm}$ between rows and $10 \mathrm{~cm}$ between the seeds within each row. After one week of germination, the mulches were applied and the bean crops were labelled using field tags from D1 to D30 in each plot for uniform data collection. The plots were watered at intervals of one day from the previous watering during the first three weeks after planting when there was no rainfall. The beans were weeded three times throughout the growth period.

\section{Data collection}

Data collection on growth parameters started in the second week after planting due to nonuniform germination in the first week after planting as some seedlings had not emerged from the ground. Plant yield data was collected at a one- week interval for 5 weeks as this is the range of time when there is vigorous vegetative growth in beans (Chinthapalli et al., 2015). The data on the number of leaves and branches was collected by counting them from the field while plant height was established by measuring using a tape measure from the ground level up to the apex of the stem (WikiHow, n.d.). The beans were harvested by uprooting in the ninth week after planting, when they had turned yellowishbrown. Pods were plucked off and packed in labelled polythene bags for each plant and transported to the laboratory to collect data on productivity parameters (Gyamfi, 2017). The pods produced per plant were initially counted and then unshelled in labelled polythene bags. To collect data on the economic yield, the total number of seeds produced per plant in each plot for all the replications were weighed using a digital weighing scale (Gyamfi, 2017).

\section{Data analysis}

SPSS (version 20) statistical package was used for descriptive statistics. Microsoft Excel 2013 and Minitab 14 Demo software were used for graphical data presentation. Homogeneity of variance was tested using Levene's (L) test, and 
Shapiro-Wilk test used for normality tests. Oneway Analysis of variance (ANOVA) was used for hypothesis inference for each objective at $5 \%$ level of significance. The Least Significant Difference (LSD) under the post hoc comparisons were used to evaluate pair wise differences among the group means.

\section{Results}

Effects of poultry manure/litter and N: P: K 17:17:17 on the growth of Rhizobia inoculated and non-inoculated bio-fortified NAROBEAN 2 variety

\section{Number of leaves}

In the second, third, fourth, fifth and sixth weeks after planting, N: P: K 17:17:17, N: P: K 17:17:17,
N: P: K 17:17:17, Rhizobia + Poultry litter and Rhizobia + Poultry litter respectively gave the highest number of leaves (Figure 1). The beans grown under sole N: P: K 17:17:17 and Rhizobia + Poultry litter had the highest and the same mean number of leaves ( $35 \pm 6 \mathrm{SE}$ ). The mean number of leaves was lowest for beans grown under the control $(27 \pm 5 \mathrm{SE})$. All the treatments showed no significant effect $(p=0.814)$ on the number of leaves in NAROBEAN 2 variety. The Post hoc multiple comparisons revealed that all the pairwise mean differences on the number of leaves for each treatment were not significantly different from each other $(p>0.05)$. Beans grown under sole N: P: K 17:17:17 and Rhizobia + Poultry litter showed no difference in the mean number of leaves.

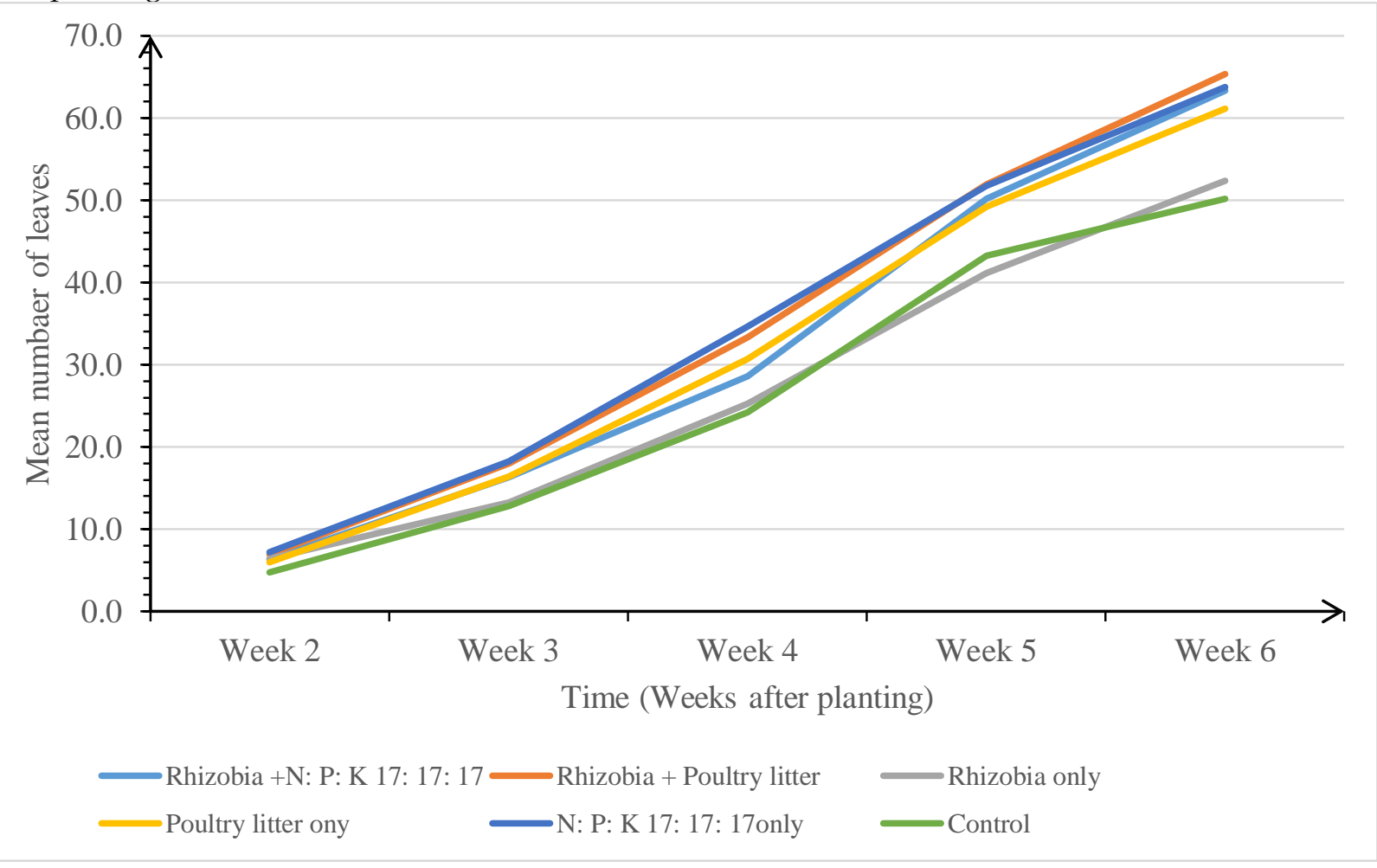

Figure 1. the effect of the treatments on the number of leaves

\section{Number of branches}

In the second week, Rhizobia + Poultry litter gave the highest number of branches. In the third, fourth, fifth and sixth weeks after planting, N: P: K 17:17:17, N: P: K 17:17:17, N: P: K 17:17:17 and Rhizobia + Poultry litter gave the highest number of branches respectively (Figure 2). The number of branches were not significantly different $(p=0.847)$ for all the treatments. The mean number of branches was highest for beans grown under N: P: K 17:17:17 only (11.2+1.9 SE) and Rhizobia + Poultry litter (11.2 \pm 2.0 S.E) and lowest for beans under the control $(8.6 \pm 1.6 \mathrm{SE})$. The Post hoc multiple comparisons of the pair 
wise mean differences showed that all the mean differences on number of branches for each treatment were not significantly different from each other $(p>0.05)$. However, beans grown under N: P: K 17:17:17 only and Rhizobia + Poultry litter had the lowest mean difference (0.73) for the number of branches.

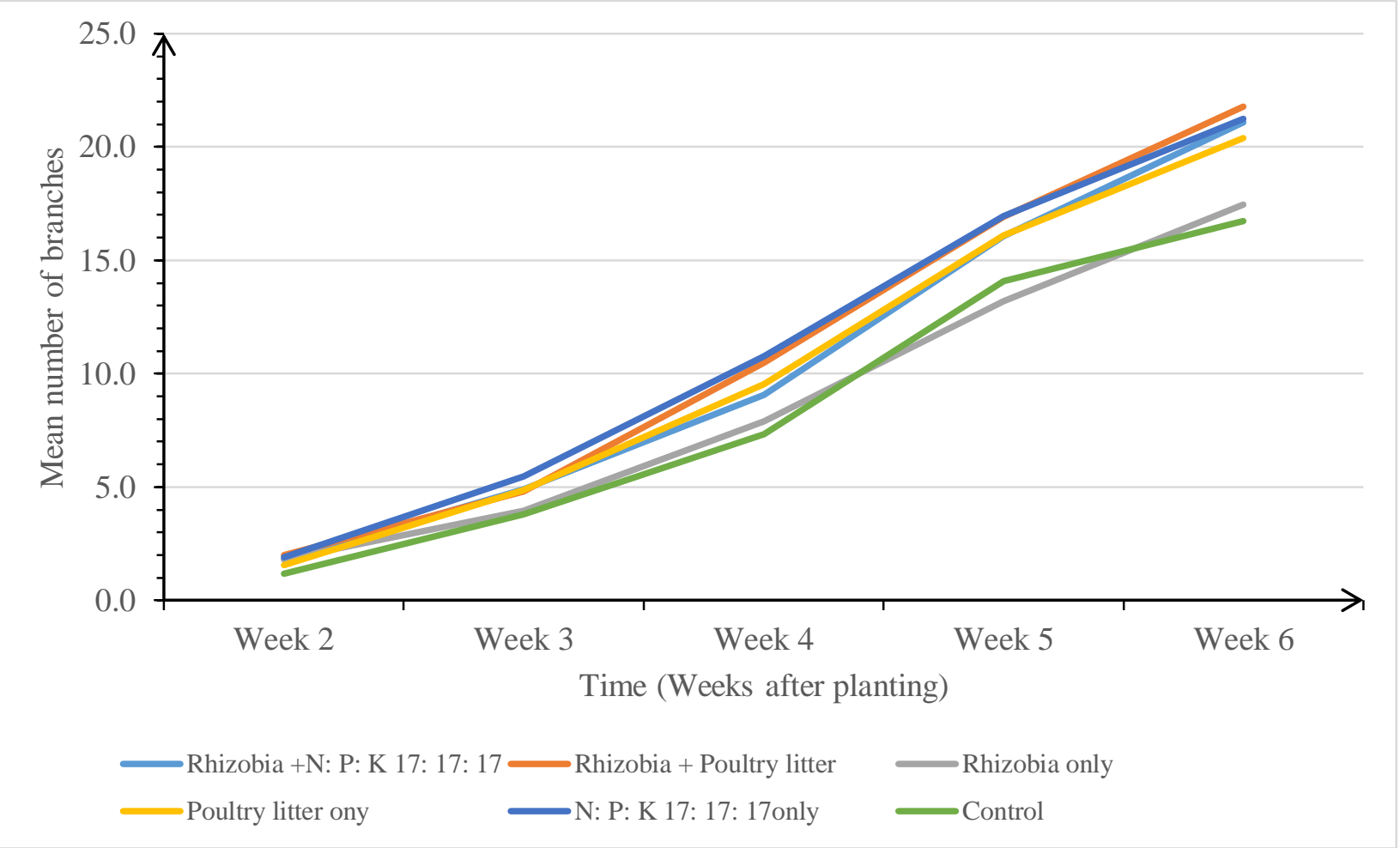

Figure 2. Effect of the treatments on the number of branches

\section{Shoot height}

In the second, third, fourth, fifth and sixth weeks, Rhizobia + Poultry litter, Rhizobia + Poultry litter, N: P: K 17:17:17, N: P: K 17:17:17 and N: P: K 17:17:17 gave the highest shoot height respectively (Figure 3 ). The beans grown under sole N: P: K 17:17:17 and Rhizobia + Poultry litter generally attained the highest shoot height of $37.6 \pm 4.9 \mathrm{SE} \mathrm{cm}$ and $36.8 \pm 4.2 \mathrm{SE}$ $\mathrm{cm}$ respectively while shoot height was lowest for beans grown under the control $(29.3 \pm 3.1 \mathrm{SE}$ $\mathrm{cm})$. The effects of the treatments on the shoot height were not significantly different from each other $(p=0.540)$. The Post hoc comparisons revealed that all mean differences in shoot height for all the treatments were not significantly different from each other $(p>0.05)$. Sole N: P: K 17:17:17 and Rhizobia + Poultry litter treatments had the lowest mean difference for the shoot height $(0.8 \mathrm{~cm})$. Generally, beans grown under sole N: P: K 17:17:17 had the highest mean growth, followed by Rhizobia + Poultry litter, Rhizobia + N: P: K 17:17:17, Poultry litter only, Rhizobia only, and lastly the control (Figure 4). 


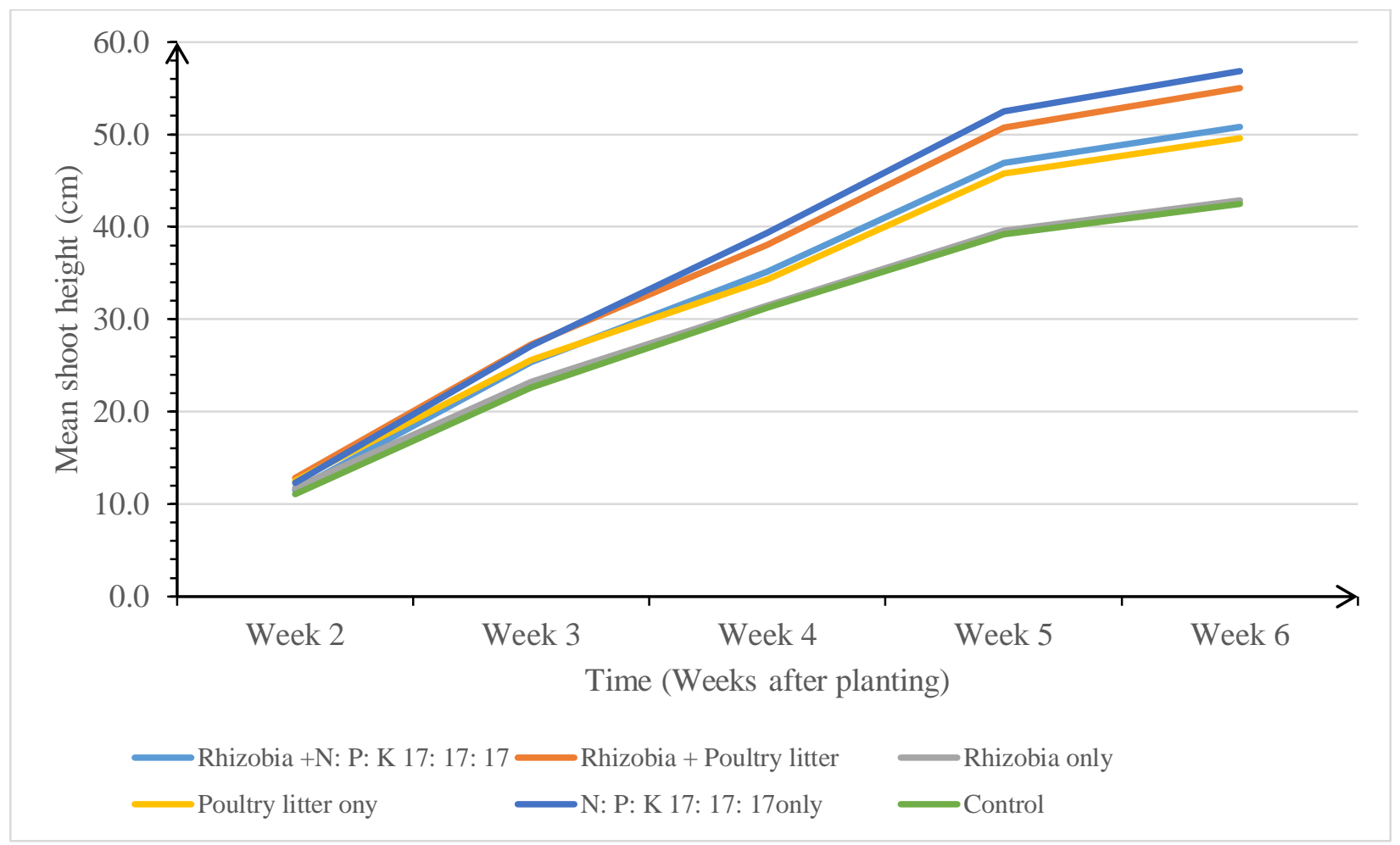

Figure 3. The effects of the different treatments on the shoot height

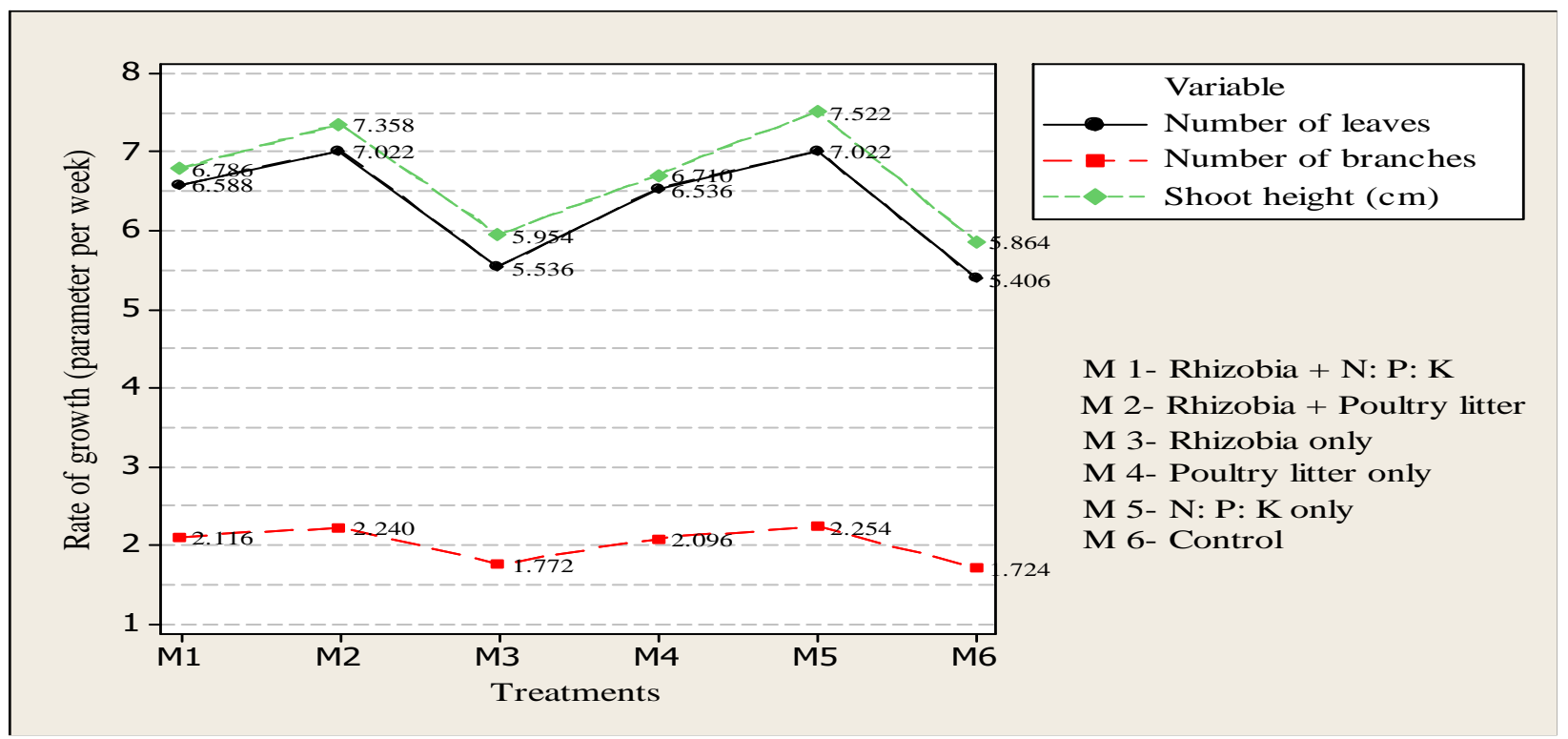

Figure 4. The combined comparison of the effects of the treatments on the rate of growth of the NAROBEAN 2 variety 
Effects of Poultry litter and N: P: K 17:17:17 on the number of pods produced per plant in rhizobia inoculated and non-inoculated biofortified NAROBEAN 2 variety

The number of pods produced per plant were statistically different $(p=0.001)$. The beans grown under N: P: K 17:17:17 only had the highest number of pods per plant and were pairwise significantly different $(p \leq 0.05)$ from the beans grown under Rhizobia only $(p=0.023)$ and the control $(p=0.000)$, but not significantly different from the other treatments $(p>0.05)$. The post hoc pairwise mean difference on number of pods produced per plant under other treatments (M1, M2, M3, M4) were significantly different from the control (M6) ( $\mathrm{p} \leq 0.05)$. N: P: K 17:17:17 only and Rhizobia + Poultry litter treatments had the least mean difference (1.1) for the number of pods per plant. (Figure 5).

Effects of Poultry litter and N: P: K 17:17:17 on the economic yield in Rhizobia inoculated and non-inoculated bio-fortified NAROBEAN 2 variety

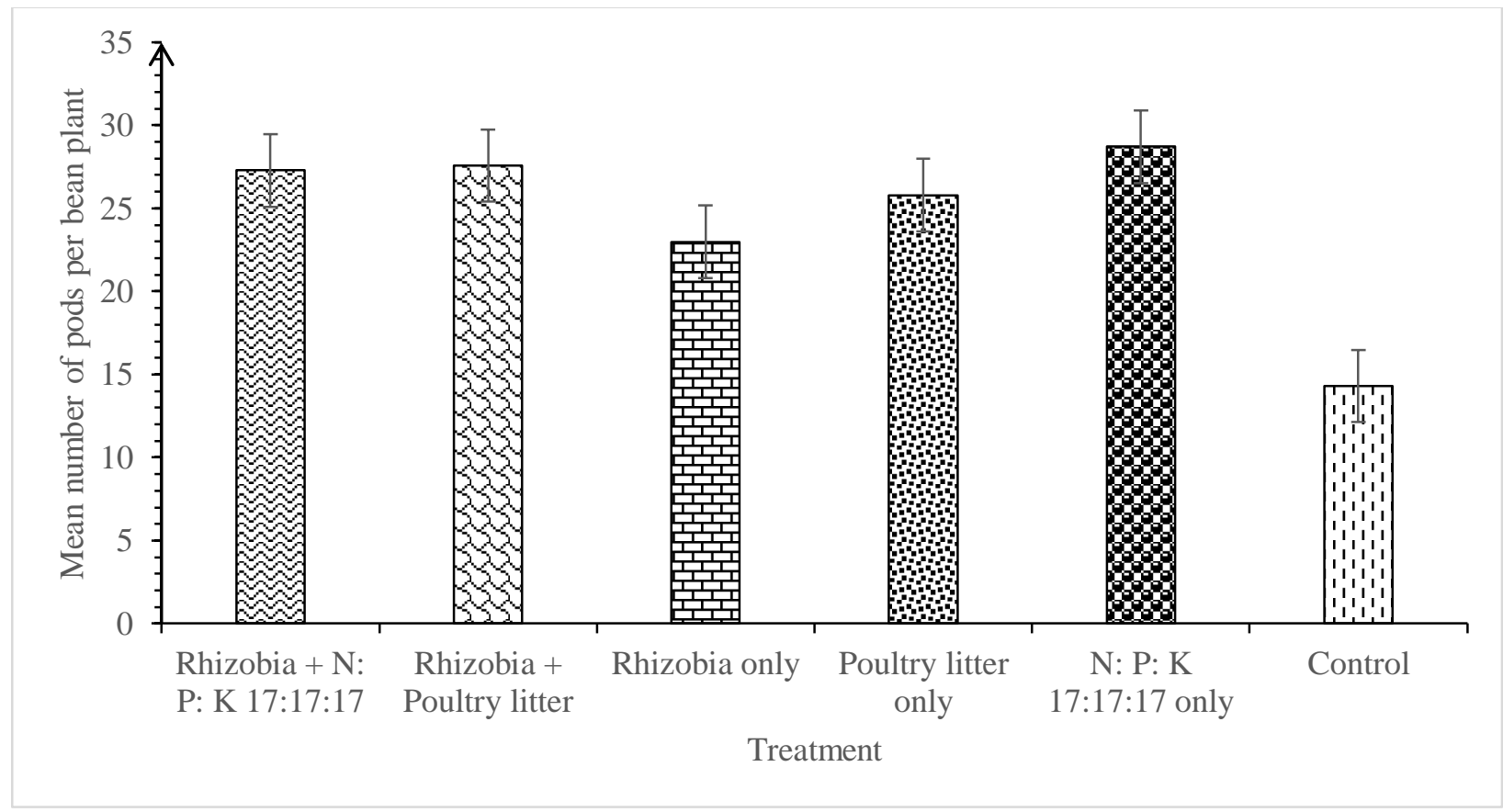

Figure 5. Effect of the treatments on the number of pods produced per plant

The effects of the treatments on the economic yield of NAROBEAN 2 is represented in Figure 6 . The beans grown under N: P: K 17:17:17 only gave the highest economic yield $\left(5.82 \mathrm{t} \mathrm{ha}^{-1}\right)$ and the control produced the least economic yield (2.73 $\mathrm{t} \mathrm{ha}^{-1}$ ) (Table 2). The economic yield of NAROBEAN 2 was significantly affected by the treatments $(p=0.001)$. The post hoc comparisons revealed that the economic yield for the beans grown under N: P: K 17:17:17 was significantly different $(p \leq 0.05)$ from the beans grown under the control but was not significantly different from the other treatments $(p>0.05)$. N: P: K 17:17:17 only and Rhizobia + Poultry litter had the lowest mean difference in the economic yield $\left(0.3\right.$ t ha $\left.^{-1}\right)$. 


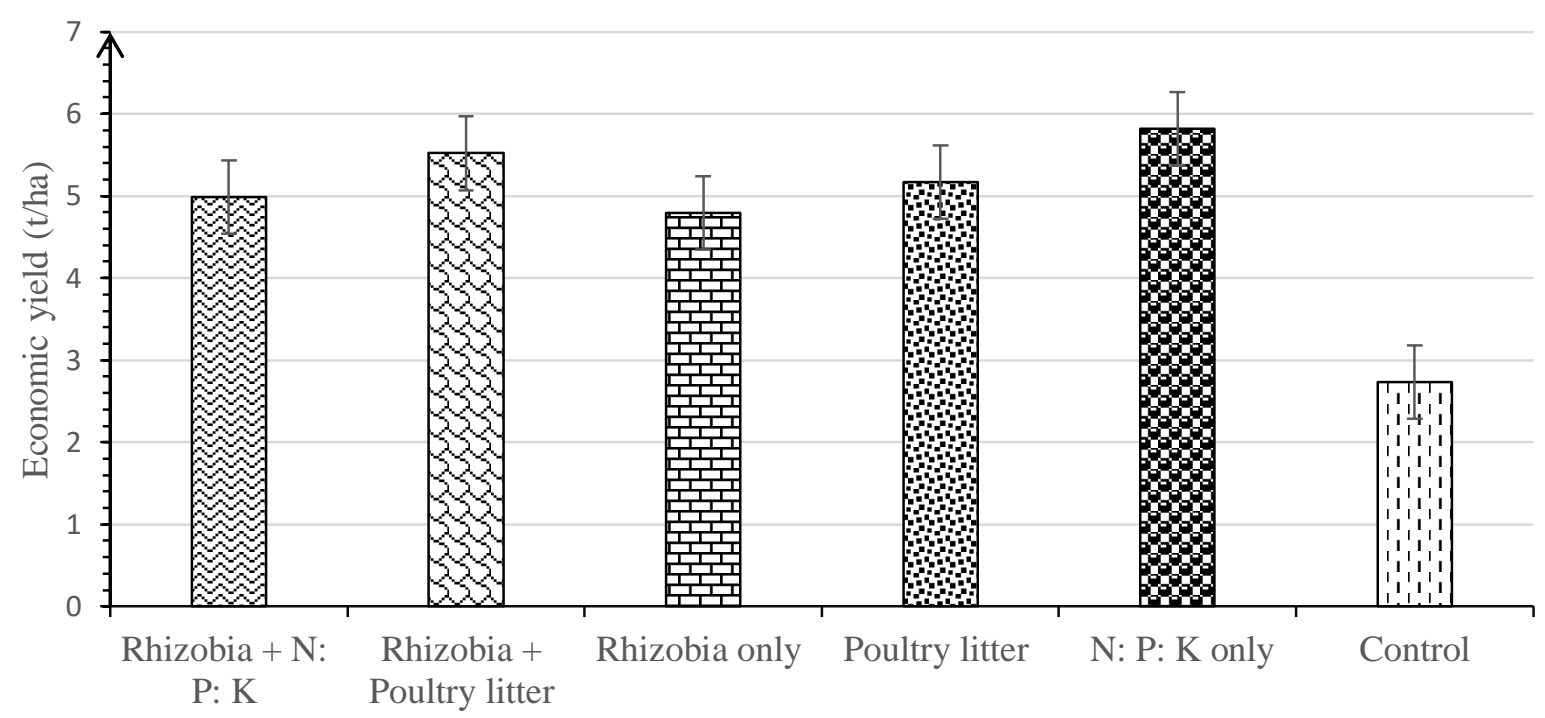

Treatments

Figure 6. The effects of the treatments on the economic yield of NAROBEAN 2

Table 2. The effect of the treatments on the economic yield of NAROBEAN 2

\begin{tabular}{|c|c|c|}
\hline Treatments & $\begin{array}{l}\text { Economic yield per bean } \\
\text { plant }(\mathrm{g})\end{array}$ & $\begin{array}{l}\text { Economic yield } \mathrm{t} \mathrm{ha}^{-1} \\
\text { (SE) }\end{array}$ \\
\hline $\begin{array}{l}\text { Rhizobia (250 g } 15 \mathrm{~kg}^{-1} \text { of seeds) + N: P: K } \\
\text { 17:17:17 (20.3 kg ha-1) }\end{array}$ & $66.6(6.9)$ & $4.99(0.52)$ \\
\hline 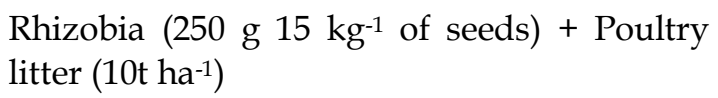 & $73.6(3.1)$ & $5.52(0.23)$ \\
\hline Rhizobia only ( 250 g per $15 \mathrm{~kg}$ of seeds) & $64.0(3.8)$ & $4.79(0.29)$ \\
\hline Poultry litter $\left(10 t\right.$ ha $\left.^{-1}\right)$ only & $69.0(3.2)$ & $5.17(0.24)$ \\
\hline N: P: K 17:17:17 (20.3 kg ha-1) only & $77.6(6.3)$ & $5.82(0.47)$ \\
\hline Control (no application amendment) & $36.4(3.9)$ & $2.73(0.29)$ \\
\hline$p$-value & 0.001 & 0.001 \\
\hline
\end{tabular}

The numbers in the brackets represent the Standard Error 


\section{Discussion}

\section{Growth response of NAROBEAN 2 under all treatments}

The observed higher growth of NAROBEAN 2 variety grown under all the treatments as compared to the beans grown under the control was due to more nutrients supplied for the growth of NAROBEAN 2 compared to the soils where no fertilizer was applied. This agrees with the study findings by (Khalid et al., 2014) in which egg plants grown on soils applied with poultry manure and N: P: K 17:17:17 grew faster than those grown on soils where no fertilizer was applied. The higher growth response of beans under rhizobia + poultry litter and poultry litter only than under Rhizobia only and the control could be explained by the capacity of the animal manure to improve the soil physical properties like soil structure which increases the soil water retention capacity and enhances the nutrient uptake and Rhizobial activities in the soil. This is in agreement with the early studies of Dauda et al., (2008) which affirmed the positive growth effects of poultry manure and revealed its capacity to improve the soil properties such as soil porosity, aggregate stability, hydraulic conductivity and the soil infiltration process. These soil amendments increase nutrient uptake and as a result enhance the vegetative growth of the crops.

The lower growth of the beans under 'Rhizobia only' inoculant as compared to the other treatments excluding the control was due to the suppressive effects of the competitive native rhizobia in the soil which minimized the inoculant's effectiveness on nodulation and the general plant growth. Native rhizobia strains compete with the inoculant for the infection sites on the roots hence reducing inoculant's effectiveness (Ham et al., 1971). This was in agreement with Payakapong et al., (2004) who reported high soil nitrogen concentrations and the strain's interaction with the other native strains of rhizobia in the soil as among the causes of ineffectiveness of rhizobia inoculant.

The higher growth of the beans inoculated with Rhizobia only than the beans under the control showed that bio fertilizer application likely increases the growth parameters in the legumes more than non-bio fertilized legumes.

Beans under plots applied with N: P: K $17: 17: 17$ only having the highest growth was due to the fast-initial release of nutrients into the soil in desired amounts making them readily available to the beans as compared to the other treatments. Though poultry litter has high nutrient content, it releases them slowly. Phosphorus being important for the physiological and developmental process, it is highly required in the soil at the early stages of crop growth to accelerate the growth physiological processes leading to increased nitrogen absorption by the plants. It is highly demanded by the crops during the three growth stages; at start of flowering, vegetative phase and seed filling stage (Kellman, 2008). Therefore, the beans under N: P: K 17:17:17 only had phosphorus that was more readily available than other beans under the other treatment combinations and the control.

Rhizobia + N: P: K 17:17:17 could have excessively fixed nitrogen by both the action of rhizobia inoculant and the inorganic nitrogen released by N: P: K 17:17:17 leading to a lower growth response as opposed to beans under N: P: K 17:17:17 only. The excessive nitrogen causes nutrient imbalances in the soil leading to the depletion of the other important minerals like calcium (Ca), phosphorus $(\mathrm{P})$ and magnesium $(\mathrm{Mg})$ and this results in the lower rate of growth. Excessive nitrogen imposes effects, ranging from negatively affecting growth, productivity, colour and flavour of the fruits, to sugar and the vitamin content of the crops (Khalid et al., 2014). Though N: P: K 17:17:17 releases nutrients quickly into the soil, its combination with Rhizobia inoculant is likely to be less effective in promoting the growth and productivity of NAROBEAN 2.

The faster release and dissolution of the nutrients in N: P: K 17:17: 17 only explains the higher performance of beans grown under $\mathrm{N}$ : P: K 17:17: 17 only as opposed to those under 
poultry litter. Though poultry litter contains useful nutrients for the growth of the beans, they are in crude form and so are relatively released slowly (Nyankanga et al., 2012) hence slower growth of beans under Rhizobia + Poultry litter and Poultry litter only. Carbon is a vital source of energy and nutrient source to the Rhizobia resulting into increase in the nodulation, nitrogen fixation and therefore very much similar growth rate of beans under N: P: K 17:17:17 only and Rhizobia + Poultry litter. The addition of poultry litter enhanced the activity of Rhizobia due to the high carbon content of the litter (Ramana et al., 2002).

Though poultry litter as an organic fertilizer releases nutrient slowly, Rhizobia inoculant had a more synergistic relationship with poultry litter and so increased its effectiveness. This synergism reinforced poultry litter to release nitrogen, phosphorus and potassium and trace elements such as calcium, manganese, iron and Sulphur, which promoted growth, physiological and meristematic activities of the beans. This promoted synthesis of photo assimilates, culminating into increased vegetative growth of the crops (Dauda et al., (2008). Therefore, Rhizobia inoculant had a more synergistic relationship with poultry litter than N: P: K $17: 17: 17$ in facilitating growth of the beans. Hence the highest growth of beans under $\mathrm{N}$ : P: K 17:17:17 only and a very marginal difference from those under Rhizobia + Poultry litter on the growth of NAROBEAN 2 variety as opposed to those under Rhizobia + N: P: K 17:17:17.

Beans under N: P: K 17:17:17 only could have received enough nutrients at early stages due to faster rate of release of the nutrients especially phosphorus by N: P: K 17:17:17 hence the highest number of pods compared to the other treatments. Also studies by Achakzai \& Bangulzai, (2006) on soybeans showed increase in number of pods with the increase in the nitrogen content of the soil. Hasanuzzaman et al., 2018 also reported high phosphorus concentration to increase the number of the pods in soybeans. Poultry litter is good at retaining the soil moisture which in turn increases the dissolution of phosphorus, a key factor in pod formation among the legumes (Nyende, 2000). This explains the very close effects of $N$ : P: K 17:17:17 only and Rhizobia + Poultry litter on pod formation as compared to the other treatments.

\section{Economic yield}

The treatments provided extra external nutrients which increased the economic yield as opposed to beans under the control which only relied on the natively available soil nutrients. It is further clarified by Khalid et al., (2014) that phosphorus is very important for flowering and fruit formation while potassium is vital in the process of seed setting in the crops. Therefore, the other treatments significantly supplied these elements more than the control.

Both N: P: K 17:17:17 only and Rhizobia + Poultry litter could have efficiently supplied the right quantities of nutrients required for maximizing the economic yield of NAROBEAN 2 than other treatments and the control. The highest economic yield observed in beans under sole N: P: K 17:17: 17 and Rhizobia + Poultry litter respectively was due to their previously explained effect on growth. This could have increased the leaf area index, consequently increasing light interception, and photosynthetic rate, and so the observed higher productivity than in the other treatments. Increased plant height increases grain yield of the crops (Caliskan et al., 2008) and enough leaves receive enough light at the reproductive stage, maximizing the yielding of the crops (Mellendorf, 2011). Therefore, the extent of the effect of each treatment on the growth of NAROBEAN 2 had a direct effect on its economic yield.

\section{Conclusion}

The effect of the various treatments on the growth and productivity parameters was generally in the order of N: P: K 17:17:17 only $>$ Rhizobia + Poultry litter $>$ Rhizobia + N: P: K 17:17:17> Poultry litter only> Rhizobia only> control. Either N: P: K 17:17:17 only or Rhizobia + Poultry litter are best interventions for improving productivity of NAROBEAN 2. The 
combination of Rhizobia inoculant with Poultry litter is very synergistic and hence is likely to release the soil nutrients relatively faster than poultry litter only. However, combining rhizobia inoculant and N: P: K 17:17:17 lowers the general growth and productivity of NAROBEAN 2 and possibly other legumes. It causes the surge of nutrients released by $\mathrm{N}$ : $\mathrm{P}: \mathrm{K}$ 17:17:17 hence slowing down the Rhizobia activity. With minimal inputs of using Rhizobia + Poultry litter as a soil amendment practice, production of nutritious NAROBEAN 2 in Uganda will increase. This will consequently increasee accessibility of the variety by low income earners who cannot afford the expensive food sources of iron and zinc, and hence to some extent combat malnourishment and increase food security. The rhizobium inoculant will also reduce the need for application of inorganic fertilizers and consequently reduce their negative ecological impact on the environment.

\section{Acknowledgement}

We are grateful to Dr. Grace KagoroRugunda for her contribution toward the development of this study, and to Sr. Dr. Jane Yatuha for identifying NARO MBAZARDI as a favourable institution for conducting the experimental part of the study. We are indebted to the NARO MBAZARDI which provided land, NARO BEAN 2 seeds and the technical assistance during this research. We appreciate the Director of Research, Dr. Kharid Kirunda for the authorization of the study, Mr. John Bosco Muhumuza who was the supervisor at the institute, Ms. Hellen Mutenyo, a senior crop technician for the devoted efforts in making this research a successful one. The Department of Biology, Mbarara University of Science and Technology (MUST) is highly valued for the technical support.

\section{References}

Achakzai, A. K. K., \& Bangulzai, M. I. (2006). Effect of various levels of nitrogen fertilizer on the yield and yield attributes of pea (Pisum sativum L.) cultivars. Pakistan Journal of Botany, 38(2), 331.

Akanbi, W. B., Olaniran, O. A., Olaniyi, J. O., Ojo, M. A., \& Sanusi, O. O. (2007). Effect of cassava peel compost on growth and nutritional quality of Celosia (Celosia argentea L.). Research Journal of Agronomy, 1(3), 110-115.

Al-abdalall, A. H. A. (2008). Pathological Studies of Fungi Associated with Pulse Seeds during Storage in Dammam Province, Kingdom of Saudi Arabia. 1993.

Bala, A., Karanja, N., Murwira, M., Lwimbi, L., Abaidoo, R., \& Giller, K. (2011). N2Africa Putting nitrogen fixation to work for smallholder farmers in Africa Production and use of Rhizobial inoculants in Africa. 21 (January). http://www.n2africa.org/ sites/n2africa.org/files/images/N 2Africa_Production and use of rhizobial inoculants in Africa.pdf

Birachi, E., Ochieng, J., Wozemba, D., Ruraduma, C., Niyuhire, M., \& Ochieng, D. (2011). Factors influencing small-holder farmers' bean production and supply to market in Burundi. African Crop Science Journal, 19(4), 335-342.

Bolan, N. S., Szogi, A. A., Chuasavathi, T., Seshadri, B., Rothrock Jr, M. J., \& Panneerselvam, P. (2010). Uses and management of poultry litter. World's Poultry Science Journal, 66(4), 673-698.

Booklets Mpeke Town. (n.d.). Retrieved September 10, 2020, from ooklets/ https://mpeketown.com/b

Broughton, W. J., Hernandez, G., Blair, M., Beebe, S., Gepts, P., \& Vanderleyden, J. (2003). 
Beans (Phaseolus spp.)-model food legumes. Plant and Soil, 252(1), 55-128.

Caliskan, S., Ozkaya, I., Caliskan, M. E., \& Arslan, M. (2008). The effects of nitrogen and iron fertilization on growth, yield and fertilizer use efficiency of soybean in a Mediterranean-type soil. Field Crops Research, 108(2), 126-132.

Chinthapalli, B., Dibar, D. T., Chitra, D. S. V., \& Leta, M. B. (2015). A comparative study on the effect of organic and inorganic fertilizers on agronomic performance of faba bean (Vicia faba L.) and pea (Pisum sativum L.). Agriculture, Forestry and Fisheries, 4(6), 263-268.

Dauda, S. N., Ajayi, F. A., \& Ndor, E. (2008). Growth and yield of water melon (Citrullus lanatus) as affected by poultry manure application. J. Agric. Soc. Sci, 4(3), 121-124.

De Benoist, B., \& Mclean, E. (2008). Worldwide prevalence of anaemia 1993-2005 who Global database on anaemia.

https://stacks.cdc.gov/view/cdc $/ 5351$

Drew, E., Herridge, D., Ballard, R., Hara, G. O., Deaker, R., Denton, M., Yates, R., Gemell, G., Hartley, $\quad$ E., Phillips, L., Seymour, N., Howieson, J., \& Ballard, N. (2012). Inoculating Legumes: practical guide (Vol. 3).

Ellis, L., Love, S., Moore, A., \& de HaroMartí, M. E. (2013). Composting and using backyard poultry waste in the home garden. Publication No. CIS, 1194.

Georgina, S. (2016). First drought-resilient, high iron beans for Uganda released. Retrieved September 10, 2020, from

https://blog.ciat.cgiar.org/firstdrought-resilient-high-ironreleased/
Godfrey, S., \& Dickens, O. (2015). Fertilizer consumption and fertilizer use by crop in Uganda. 29.

https://africafertilizer.org/wpcontent/uploads/2017/05/FUBCUganda-final-report- 2015.pdf

Guide 2 Uganda. (2016). New bean varieties versus the ordinary ones. Retrieved September 10, 2020, from https://guide2uganda.ug/newbean-varieties-versus-theordinary-ones/

Gyamfi, Y. (2017). Effects of NPK and poultry manure rates on the growth, nitrogen fixation and grain yield of soybean (Glycine max (l) Merrill) (Doctoral dissertation).

Ham, G. E., Cardwell, V. B., \& Johnson, H. W. (1971). Evaluation of Rhizobium japonicum Inoculants in Soils Containing Naturalized Populations of Rhizobia 1. Agronomy Journal, 63(2), 301-303.

Hasanuzzaman, M., Fujita, M., Oku, H., Nahar, K., \& Hawrylak-Nowak, B. (2018). Plant nutrients and abiotic stress tolerance. Plant Nutrients and Abiotic Stress Tolerance, July, 1590. https://doi.org/10.1007/978981-10-9044-8

ICRISAT. (2017). Release of biofortified bean varieties in Uganda. Retrieved September 10, 2020, from https://www.icrisat.org/releaseof-biofortified-bean-varieties-inuganda/

Katungi, E., Farrow, A., Chianu, J., Sperling, L., \& Beebe, S. (2009). Common bean in Eastern and Southern Africa: a situation and outlook analysis. International Centre for Tropical Agriculture, 61, 1-44.

Kellman, A. (2008). Rhizobium inoculation, cultivar and management effects on the growth, development and yield of common bean (Phaseolus vulgaris L.). Lincoln University.

Khalid, A. A., Tuffour, H. O., Bonsu, M., Adjei-Gyapong, T., Abubakar, A., Boateng, I. Y., Melenya, C., \& Kpotor, P. (2014). Effects of poultry 
manure and NPK fertilizer on growth and yield of garden eggs (Solanum Melongena) in a sandy soil in Ghana. International

Journal of Scientific Research in Knowledge, 2(6), 257.

MAAIF (Ministry of Agriculture Animal Industry and Fisheries) (2010). Agriculture Sector Development Strategy and Investment Plan: 2010/11-2014-15. July 2010, 1-149.

Masarirambi, M. T., Hlawe, M. M., Oseni, O. T., \& Sibiya, T. E. (2010). Effects of organic fertilizers on growth, yield, quality and sensory evaluation of red lettuce (Lactuca sativa L.)'Veneza Roxa'. Agriculture and Biology Journal of North America, 1(6), 1319-1324.

Mauyo, L. W., Okalebo, J. R., Kirkby, R. A., Buruchara, R., Ugen, M., Mengist, C. T., Anjichi, V. E., \& Musebe, R. O. (2007). Technical efficiency and regional market integration of cross-border bean marketing in western Kenya and eastern Uganda. African Journal of Business Management, 1(4).

Mbatha, A. N. (2008). Influence of organic fertilisers on the yield and quality of cabbage and carrots (Doctoral dissertation, University of the Free State).

Mellendorf, N. E. (2011). Soybean growth and yield response to interplant competition relief in various plant density environments.

Mofunanya, A. A. J., Ebigwai, J. K., Bello, O. S., \& Egbe, A. O. (2015). Comparative study of the effects of organic and inorganic fertilizer on nutritional composition of Amaranthus spinosus L. Asian Journal of Plant Sciences, 14(1), 3439.

ps.2015.34.39

https://doi.org/10.3923/aj

Muhammad, D., \& Khattak, R. A. (2009). Growth and nutrient concentrations of maize in pressmud treated saline-sodic soils. Soil and Environment (Pakistan).

Nankinga, O., \& Aguta, D. (2019). Determinants of Anemia among women in Uganda: further analysis of the Uganda demographic and health surveys. BMC Public Health, 19(1), 1-9.

Nekesa, P., Maritim, H. K., Okalebo, J. R., \& Woomer, P. L. (1999). Economic analysis of maize-bean production using a soil fertility replenishment product (PREP-PAC) in western Kenya. Afr Crop Sci J, 7(4), 585-590.

Nyankanga, R. O., Onwonga, R. N., Wekesa, F. S., Nakimbugwe, D., Masinde, D., \& Mugisha, J. (2012). Effect of inorganic and organic fertilizers on the performance and profitability of grain amaranth (Amaranthus caudatus L.) in Western Kenya. Journal of Agricultural Science, 4(1), 223.

Nyende, P. (2000). Effect of soil fertility and weed management on the performance offinger millet in eastern Uganda. MSc thesis, Makerere University, Kampala, Uganda. 85pp.

Payakapong, W., Tittabutr, P., Teaumroong, N., \& Boonkerd, N. (2004). Soybean cultivars affect nodulation competition of Bradyrhizobium japonicum strains. World Journal of Microbiology and Biotechnology, 20(3), 311-315.

Ragagnin, V. A., Sena Júnior, D. G. de, Dias, D. S., Braga, W. F., \& Nogueira, P. D. M. (2013). Growth and nodulation of soybean plants fertilized with poultry litter. Ciência e 24. Agrotecnologia, 37(1), 17-

Ramana, S., Biswas, A. K., Singh, A. B., \& Yadava, R. B. R. (2002). Relative efficacy of different distillery effluents on growth, nitrogen fixation and yield of groundnut. Bioresource Technology, 81(2), 117-121. 
Ravikumar, R. (2012). Growth effects of Rhizobium inoculation in some legume plants. Int J Curr Sci., 1888, 1-6.

Roberts, T. L. (2009). The role of fertilizer in growing the world's food. Better Crops, 93(2), 12-

15.

UNICEF-WHO-The World Bank. (2017). Levels and trends in child malnutrition, Joint Child Malnutrition Estimates, Key findings of the 2017 edition. UNICEFWHO-The World Bank, 1-16. https://data.unicef.org/wpcontent/uploads/2017/06/JME-

2017_brochure_June-25.pdf WikiHow. (n.d.). 4 Ways to Measure Growth Rate of Plants. Retrieved September 10, 2020, from https://www.wikihow.com/Meas ure-Growth-Rate-of-Plants. 